\title{
Scalar timing law for interval timing in a plastic network of spiking neurons
}

\author{
Jeff Gvornik ${ }^{1^{*}}$, Harel Shouval ${ }^{2}$ \\ From Nineteenth Annual Computational Neuroscience Meeting: CNS*2010 \\ San Antonio, TX, USA. 24-30 July 2010
}

In many perceptual tasks there is an observed linear relationship between the magnitude of the estimated variable and the error of the estimate; this is called Weber's law. Applied to estimates of interval timing this general linear relationship is called the scalar timing law. Under a stronger variant of the law in addition to the standard deviation of the errors increasing linearly with time, the complete distribution of timing estimates scales linearly as well.

We have recently developed a model of a plastic network that can represent time through learned temporal dynamics [1]. The temporal representations formed in our network resemble those described experimentally in V1 [2]. Here we train this network to encode various times from several hundred ms to slightly less than 2 sec. We decode this spiking model using a simple population decoding scheme. We show that the standard deviation of reported durations in such a spiking network, scales nearly linearly. We analyze how the slope and intercept of linear fits depend on system parameters such as number of neurons, and network noise levels. Although the error scales linearly with time, the distribution of the decoded times does not scale linearly with the time, and its shape changes. We examine the effect of including an additional source of noise in the decoding process. We show that if an additional source of noise exists in the decoding process, the response distribution can scale nearly linearly as well. We analyze how this additional noise source effect the slope and intercept of the linear fit, and what magnitude of noise is necessary for obtaining linear scaling of the distribution.

\section{Acknowledgements}

This work was supported by a Collaborative Research in Computational Neuroscience grant, National Science Foundation Grant 0515285.

\footnotetext{
* Correspondence: harel.shouval@uth.tmc.edu

${ }^{1}$ Brain and Cognitive Sciences, MIT, Cambridge, MA, USA
}

Author details

${ }^{1}$ Brain and Cognitive Sciences, MIT, Cambridge, MA, USA . ${ }^{2}$ Department of Neurobiology and Anatomy, The University of Texas Medical School at Houston, USA.

Published: 20 July 2010

\section{References}

1. Gavornik JP, Shuler MG, Loewenstein Y, Bear MF, Shouval HZ: Learning reward timing in cortex through reward dependent expression of synaptic plasticity. Proc Natl Acad Sci U S A. 2009, 106(16):6826-31.

2. Shuler MG, Bear MF: Reward timing in primary visual cortex. Science 2006, 311(5767):1606-9.

doi:10.1186/1471-2202-11-S1-P104

Cite this article as: Gvornik and Shouval: Scalar timing law for interval timing in a plastic network of spiking neurons. BMC Neuroscience 2010 11(Suppl 1):P104.
Submit your next manuscript to BioMed Central and take full advantage of:

- Convenient online submission

- Thorough peer review

- No space constraints or color figure charges

- Immediate publication on acceptance

- Inclusion in PubMed, CAS, Scopus and Google Scholar

- Research which is freely available for redistribution

Submit your manuscript at www biomedcentral.com/submit
C Biomed Central 